This item was submitted to Loughborough's Research Repository by the author.

Items in Figshare are protected by copyright, with all rights reserved, unless otherwise indicated.

\title{
Content model as a tool for re-designing services at transformational level: case study of Education for Sustainable Development (ESD)
}

\section{PLEASE CITE THE PUBLISHED VERSION}

http://doi.org/10.1504/JDR.2018.10012175

\section{PUBLISHER}

(C) Inderscience

\section{VERSION}

AM (Accepted Manuscript)

\section{PUBLISHER STATEMENT}

This work is made available according to the conditions of the Creative Commons Attribution-NonCommercialNoDerivatives 4.0 International (CC BY-NC-ND 4.0) licence. Full details of this licence are available at: https://creativecommons.org/licenses/by-nc-nd/4.0/

\section{LICENCE}

CC BY-NC-ND 4.0

\section{REPOSITORY RECORD}

Kuzmina, Ksenija, Tracy Bhamra, and Rhoda Trimingham. 2019. "Content Model as a Tool for Re-designing Services at Transformational Level: Case Study of Education for Sustainable Development (ESD)". figshare. https://hdl.handle.net/2134/27645. 


\title{
Content model as a tool for re-designing services at transformational level: case study of Education for Sustainable Development (ESD)
}

\author{
Author (AU)
}

Address (ADR)

\begin{abstract}
Service Designers have been working in organisations at a transformational level using tools and methods that primarily focus on the needs of the individuals. Change theories suggest that for transformational change to take place in organisations, change in individuals needs to happen in relation to change at organisational level. Thus service designers need knowledge that enables them to envision what change may look like at an organisational level. This paper presents a case study of a content model that was developed as part of the design research to represent such knowledge. The model represents education for sustainable development (ESD) as a vision of a new service provided by schools to students. It draws on empirical data collected from five schools, organisational change theory and service thinking to show the service/user relationship that needs to be developed at a school level to move schools towards the provision of ESD. The model was tested with seven service designers through in-depth interviews. The findings support understanding and usability of the model in the design process as a tool for transformation but also highlight barriers that a model as a stand-alone tool presents. Wider issues in relation to service designers engaging with transformational change within schools are also discussed.
\end{abstract}

Keywords: (ABS)

Reference

Biographical notes: (ABS)

\section{Introduction}

Service designers have been expanding their capabilities from working on the periphery of organisations to working at the level of strategies and new visions for organisations, as well as expanding participation in the design process from service users to a wider set of stakeholders (Clatworthy, 2011, Junginger and Sangiorgi, 2011). However, Bloomberg and Darrah (2014) suggest that service designers continue to work with tools and methods that largely focus on an individual in order to enable change within service organisations, such as experience journey mapping, where user insights provide the basis for the new value propositions (Miettinen, 2016). This approach aligns with the transformative learning theories of organisational change. Transformative learning theories identify an individual to be the starting point for organisational development and describe the 'internal processes that individuals go through to initiate organisational change' (Henderson, 2002). These theories place importance on individual's experiences, critical reflection on these experiences and action taken to modify existing systems in response to the needs of the individuals. 
Transformational change theories focus on change at the organisational level with change on an individual level seen as a consequence of the process (Henderson, 2002). In particular transformational change within an organisation requires alterations in the elements of the whole system (ibid.) including structure, policies and procedures, mission and strategy, leadership, and organisational culture (Schein, 1990). Based on these theories, as the new vision for the organisation is defined and is integrated into the organisation the individuals will gain understanding and belief in the new mission, gain new mental models and new behaviours (Henderson, 2002).

Whether service designers are working externally to the organisation or within, they need to understand, what are the elements that constitute change in a service at transformational level before they choose design methods to engage with it. For example, a patient-centred model in healthcare was introduced to counteract provider-centred healthcare model, which values, personal preferences and partnerships' (Delaney, 2017), As a result service designers working in the healthcare sector have adopted and developed tools with a focus on experience of the stakeholders, to enable the change in the vision and culture of healthcare organisations (Freire and Sangiorgi, 2010) as well as an overall service provision. In addition service designers need to position organisations in relation to these elements (Miettinen, 2016) before they commence work, thus having to work with tools that are context specific.

Henderson (2002) points out that these two theories are complimentary and underpin effective change in an organisation and that both need to be addressed to create it. In particular, these theories are bridged by the approach of action learning (Henderson, 2002). This is a 'context specific' approach (Pedler, et al, 2005) to develop individuals within organisations through a particular task that relies on collaborative questioning of assumptions that are taken for granted (Limerick, et al, 1994). These assumptions are in relation to organisational identity including its overall vision, values, culture, structure, and systems of action while at the same time engaging with individual needs, what Rigg (2008) calls development of 'I' and collective 'we'. Through action learning, an organisation does not only solve its problems, but develops new ways of interaction, communication, patterns of thinking, enacting change both at organisational level as well as individual (ibid.). Riggs suggests that action learning should be perceived as a process that includes experimentation and small scale prototyping within the organisation where individual as well as collective outcomes are attended to.

Kuure et.al (2014) points out that a service design process through the methods of co-creation, co-design and service prototyping can enable action learning and facilitate transformational change within organisations. These collaborative design approaches allow for the development of spaces where individuals can share information, create new knowledge, and develop new service offerings.

Transformational change therefore intertwines the change of individuals as well as the organisation and its context. Thus, by focusing on the methods and tools that primarily attend to the needs of the individual, service design narrows down their overall contribution and effectiveness of the transformational change within service organisations. Instead there is a need to engage individuals within organisations, in relation to organisational context, its vision of change and strategy to enable action learning in relation to that. Therefore service designers can benefit from engaging with tools that focus on the content of change at an organisational level.

\section{Content model as a design tool}

Young (2008) identified a content-based model to be a useful tool in a process where designers focus on socially complex change and are engaged in designing contexts. These models represent 'know that' knowledge (Young, 2008) showing a particular phenomenon in a real- world domain (Weber, 2003). Weisberg (2007) notes that the model-world relationships are many and are determined by the purpose of the model. These may be for the purpose of "expressing certain characteristics of an object, or system 
that exists, existed or might exist” (Echenique, 1963 in Young, 2008: p. 565). In design literature the latter purpose of the model is highlighted, for example, Schermann et al (2009) note that in design models can represent solutions in the domain, whereas Johnson and Henderson (2002) suggest that models can be used to "represent the idealised view of how a particular system works" (p.26).

A content-based model therefore is an effective way to make "know that" knowledge explicit. This helps designers to understand the future system (Mendel, 2012) and to engage other stakeholders in comprehending the vision of what the system might be, exploring levels of complexity within the system and developing appropriate processes of addressing them (Young, 2008). Mendel (2012) describes how the model can be used during specific stages of the design process, for example to frame and guide the discovery stage and evaluate the solutions during the design process while constituting part of the solution. Thus a content- based model is a tool that may inform both the design process as well as the solution.

In conclusion, service designers have been increasingly engaging with transformational change within service organisations. However, their approaches have been limited due to the user focused tools and methods. Following change theories, transformational change in an organisation necessitates change in individuals in relation to change in organisational vision, strategy and structure. Thus, designers need to be able to design in- context as well as contexts. In the next section, a content-based model is proposed as a tool that envisions change at organisational level to support existing user-focused design process. Thus potentially contributing to the area where 'know that' knowledge is limited to enable a more integrated transformational change in an organisation.

\section{Case Study: Understanding change towards ESD in schools}

\subsection{Background}

Education for Sustainable Development (ESD) is a vision for transforming the educational system including primary education towards a sustainable society (Wals, 2009). In England, there is general agreement on what ESD should look like within schools (Tilbury, 2011, Wals, 2009), known as the 'whole school approach' (Shallcross, 2005). 'Whole school approach' describes a desired state for ESD (Symons, 2008, Henderson and Tilbury, 2004) where sustainable development is considered in a holistic way (Hargreaves, 2008). Within such schools, all stakeholders, including pupils and the organisation, value sustainability, and express this value through active engagement in the ongoing development process (Sterling, 2003: 272). For example, exploration of local sustainable solutions within the curriculum would lead to a whole school participation in critical reflection (Shallcross, 2005: 4) of school culture, day-to-day school practices, school operations, and stakeholder and community involvement (Ferreira et. al, 2006 and Hargreaves, 2008). This ESD approach may be described as democratic (Kopnina, 2014 and Bonnett, 2006), constructivist (Kopnina, 2014), and local in nature (Bonnett, 2006). Few ESD theorists describe these as limiting factors as they promote an anthropocentric view of sustainable development linking environmental issues with human concerns (Kopnina, 2014). They argue that there is a need to reimagine human relationship with nature (Bonnett, 2006), giving nonhuman species a voice (Kopnina, 2014). However these discussions continue to stay on an ideological level and provide very little guidance on implementation (Kopnina and Meijers, 2014). Thus, for the purpose of this research, 'whole school approach' has been taken as a practical approach to ESD.

Successfully moving towards a 'whole school approach' requires schools to engage with transformational change at an organisational level, attending to individuals' and school's values, school culture and structure. The 'whole school approach' (Shallcross, 2005) has been recognised in literature to create the most value for individual pupils, schools, local communities and environment, however, very few schools have been internally motivated and capable to engage with the process. Primary educational system in England has been experiencing some external facilitation of change towards ESD for several decades (Bourn 2008) with support and leadership from the government and NGOs. The fluctuating top 
down governmental approach (Snell and Brooks-Wilson, 2012) and the topical agenda of the NGOs means that the change is limited and is rarely transformational (Bourn 2005). Instead the change that is led by the government and NGOs is known as transmissive, where knowledge and solutions are transmitted to others (Sterling, 2003). For example, a national 'Switch it off 'campaign encourages children and staff to switch off lights for one day (Actonenergy, 2013). This 'best practice' approach to ESD is limiting because it sees education as means to an end where increased awareness and scientific, factual knowledge about environmental, social and economic issues will lead to the cure of these issues through new attitudes and behaviours (Sterling, 2003). The cure is visible and can be measured for example through decreased environmental impact (Vare and Scott, 2007). This view implies universal rather than contextual knowledge and learning is instructive. While transmissive change is needed to address sustainable development issues in an urgent manner, it is very limiting, whereas transformational change will help students to gain capacity to think critically and act responsibly when faced with any problem in the long run. Thus, for the transition towards ESD to take place an externally facilitated change in schools at transformational level is needed.

Service design has a collection of tools and methods to enable transformational change. However its knowledge of the educational context, in particular the context of ESD that is required, is limited (SDRN UK, 2013). Thus for Service Design to engage with the change process, an understanding of the system's elements it seeks to redesign is needed (Steen et. al, 2011).

The common characteristic of schools moving towards ESD contextualises change within the parameters of an individual organisation (WWF-UK, 2011). Thus understanding of the design and structure of the organisational system that is moving towards ESD is necessary. Literature recognises that educational institutions are service providers (Ng and Forbes, 2009), and therefore the system that requires change is a service organisation. This definition is relevant to the work of service designers, and contributes to the understanding of the system.

The knowledge required for service designers to understand ESD in schools at organisational level could not be found within literature due to insufficient research in the area. To address this gap an empirical study with five schools was undertaken during this research, which informed a Sustainable Education Service (SES) content model.

\subsection{Methods}

The aim of the empirical study was to understand what ESD looks like in a school at an organisational level in practice. A multiple case study approach, with its focus on analytical rather than statistical generalisation was chosen, as a method that is sensitive to the unique approaches of the schools, while developing an understanding that is generalised (Yin, 1994 and Robson, 2002). Multiple-case designs require extensive resources and time and therefore should not be taken lightly (Yin, 1994). Thus the number of case studies had to be large enough to establish analytical generalisation, yet be manageable for the researcher. Five primary schools with a variety of knowledge and involvement with ESD concepts (from exemplary to negative cases (Bryman, 2004) were recruited for the purpose of this research. During the research study, three types of methods were used to provide breadth and depth to the investigation, which is known as triangulation (Denzin and Lincoln, 1998): in-depth, contextual interviews (with headteachers and staff), questionnaires (staff), analysis of documents and materials online. 'Within-case analysis' in this research was developed to draw conclusions about the phenomenon of ESD in a bounded context of a school (Miles and Huberman, 1994). Cross-case analysis was performed to increase generalisability of the research (Miles and Huberman, 1994) and to develop an understanding of ESD as change at organisational level across schools rather than within one single case. In the process of cross-case analysis, a richer understanding and explanation of conditions under which identified phenomenon happens was sought. 


\subsection{Results Overview}

It was found that all schools recognise ESD as an improvement strategy and have shown some involvement with ESD. However there is a great variation in the understanding of ESD, depth and breadth of work that the schools do. The cross-case analysis was able to identify approaches and domains within which schools explore ESD and highlighted that more sustainable schools have an understanding and vision for ESD and their role within it. They develop sustainable development issues as part of the local context, involving a wide selection of stakeholders whilst integrating all elements of the school and thus engaging with the 'whole school approach'. Schools that are less sustainable do it to a much lesser extent, have a narrow understanding of ESD, limited vision of their role within it, and integrate it with only some elements of the school and fewer individuals.

\subsection{Service Thinking Lens}

Provision of education may be described as a service provided by the service organisation, the school, to the service user, the student (Ng and Forbes, 2009). Thus service thinking (Vargo and Lusch, 2008) was used as the lens to analyse the cross-case findings further in order to provide an innovative view of the problem and to more closely align the problem with service designer.

Service thinking defines the essence of service to be value-in-use, which is generated throughout the interaction between the user and the provider (Gronroos, 2008). In this view, the role of the provider is to facilitate value to the user by providing a basis for value creation in the form of resources that may include goods, services, information and where the provider is a co-creator of values during direct engagement with the user. The user creates value through value- generating processes by interacting with the resources, contributing their own skill and resources if necessary and through having a direct interaction with the service provider (ibid.). This is a shift from the traditional view of the service where value is embedded into the goods, activities and processes that the provider produces and offers to the user by exchanging it for money or an equivalent (Vargo and Lusch, 2008, Gronroos, 2008).

Using service thinking as a lens on the findings from the cross-case analysis two types of relationship between schools and students emerged.

$1 \mathrm{~A}$

1. service (formal and informal curriculum) co-production

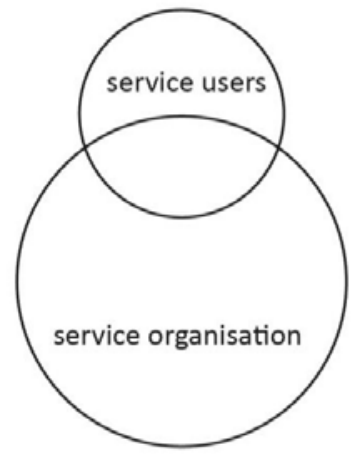

$2 \mathrm{~A}$

1. service (formal and informal curriculum) co-production

2. organisational co-development

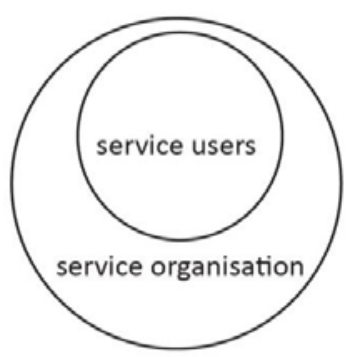

Figure 1: Overview of Two Types of Relationships Between Schools and Students 
In the first instance, students participate in their education as both informants and recipients where they are encouraged to participate in active learning (see Figure 1,1A). However, their participation is limited to the classroom and an informal curriculum. In the second instance, students are not only participants in the curriculum (formal and informal) but they also take part in the development of their school (see Figure 1, 2A). This is an additional experience rooted in critical thinking and development of empowerment in students. These relationships may be found across all schools regardless of whether or not they are moving towards sustainability. However, the empirical findings show that when applied to sustainability, these relationships determine how schools become involved with ESD (see Figure 2).

$1 \mathrm{~B}$

1. service (formal and informal curriculum) co-production 2. SD issues

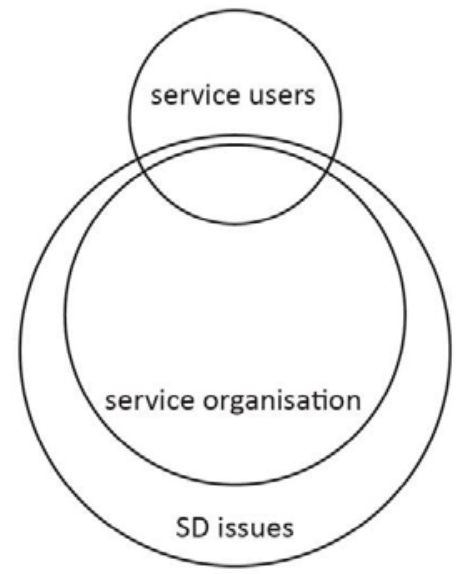

2 B

1. service (formal and informal curriculum) co-production

2. organisational co-development

3. SD issues

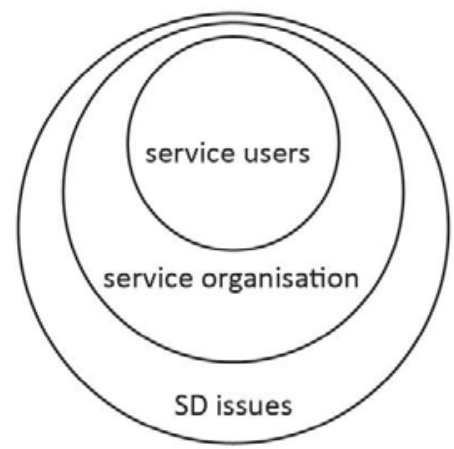

Figure 2: Configuration of the School Relationships in Schools Moving Towards ESD

In the first instance (see Figure 2, 1B), students’ participation resides within the curriculum (formal and informal) while the school engages with sustainable development issues. Therefore students' participation with sustainable development issues occurs only within the curriculum, separate to the sustainable development of the organisation. For example, students learn about fuel poverty whilst discussing the book in the English literature curriculum and as a result of it teacher plans a visit to an eco-home. In the second school/student relationship (see Figure 2, 2B), students participate in the curriculum and school development while sustainable development issues are integrated across. In this instance, students are integral to the sustainable development of the organisation in addition to experiencing sustainable development in the formal/informal curricula. For example, students learn about energy use as they undertake environmental review of the school, which they feed back to the school management with a proposed set of changes.

When seen from the service thinking perspective, it may be suggested that when the service of education is defined within the boundaries of the classroom or formal/informal curriculum then education is already aligned with Service-Dominant logic. Here, the user (the student) is encouraged to be active and the needs of the user inform the pedagogy of the school. Therefore in this case, the value of the service is already co-created between the user and service provider. However, from the empirical studies it may be observed that educational service can go beyond the 'primary' service provision. This education can be extended to include students' active participation in the development of the service organisation itself. In this case, what constitutes the service of educational institutions is extended to include organisational development. Therefore in this case, the full value of the service is only created when the service user 
actively participates in the 'primary service', or education they receive within the classroom, as well as by participating in co- development of the service organisation.

This research therefore suggests that it is the latter configuration (2B) that corresponds to the provision of sustainable education as perceived by the theory of ESD. However, this research does not suggest that other configurations should not be practiced.

The following section presents the content-based, Sustainable Education Service (SES) Model. It was developed based on the findings from the multiple case study of five schools changing towards Education for Sustainable Development combined with an organisational change model. The subsequent section reports meaning making study where the model has been presented to seven service design experts and discussed as a design tool to support integrated transformational change within a school.

\subsection{Sustainable Education Service (SES) Model Development}

The SES Model (see Table 1 and Figure 3) is based on the analysis outcomes described above and represents elements that are necessary for the school as a service organisation to provide resources to the user to co-create the value of ESD.

Therefore, the model reflects both the organisational aspects of the school whilst recognising that it is a particular type of organisation, a service organisation. These elements are also relevant to the school's transformational change process towards ESD as a service organisation. They emerged from the empirical studies and have been further identified and organised based on the Model of Organisational Performance and Change (Burke and Litwin, 1992), which is based on the transformational change theories. Burke and Litwin (1992) suggest that there are several elements within organisations that are associated with transformational change, both on organisational as well as personal levels. These include external environment, mission/strategy, leadership, culture, and individual and organisational performance. However, from the empirical studies it was also suggested that other elements, such as structure and partnerships, are also important in the ESD change and therefore these elements are also included in the SES Model.

SES Model elements are presented in Table 1 and illustrated as a model in Figure 3:

Table 1 SES Model elements

\begin{tabular}{|l|l|}
\hline SES Model element & Description \\
\hline External Environment & $\begin{array}{l}\text { Includes elements of environment that have an overall impact on the } \\
\text { organisation and its vision in relation to ESD but where the service organisation } \\
\text { has least direct control of: general preconceptions, knowledge/understanding } \\
\text { about sustainable development, governmental policies about ESD in England, } \\
\text { the organisation's local context in relation to sustainable development } \\
\text { issues/needs. }\end{array}$ \\
\hline Service Vision & $\begin{array}{l}\text { ESD service vision that the organisation develops. It integrates an internal vision } \\
\text { of holistic ESD user experience and external vision, which considers the service } \\
\text { provider's contribution within a larger sustainability movement. }\end{array}$ \\
\hline $\begin{array}{l}\text { Organisational } \\
\text { Strategy }\end{array}$ & $\begin{array}{l}\text { The strategy that the school develops to move towards its ESD vision. The } \\
\text { strategy for ESD is to consider one issue at a time and develop it across a whole } \\
\text { service. Therefore the strategy considers what is being developed and how it is } \\
\text { being developed. }\end{array}$ \\
\hline $\begin{array}{l}\text { Organisational } \\
\text { culture }\end{array}$ & $\begin{array}{l}\text { ESD organisational culture is proactive. It develops itself through strategic ESD } \\
\text { entry points: project development, curriculum formal/informal, operations }\end{array}$ \\
\hline
\end{tabular}




\begin{tabular}{|l|l|}
\hline & development and awards. These elements are integrated and numerous. \\
\hline $\begin{array}{l}\text { Organisational } \\
\text { leadership }\end{array}$ & $\begin{array}{l}\text { Organisational ESD leadership is distributed within the organisation and } \\
\text { between the service providers and the user. }\end{array}$ \\
\hline $\begin{array}{l}\text { Organisational } \\
\text { structure }\end{array}$ & $\begin{array}{l}\text { ESD organisational structure has a flat hierarchy on an organisational level, as } \\
\text { well as between the service provider and the service user. }\end{array}$ \\
\hline $\begin{array}{l}\text { Value created for } \\
\text { User/Organisation }\end{array}$ & $\begin{array}{l}\text { The outcome of ESD as a service. In ESD, the value is co-created for the user, } \\
\text { the service organisation, as well as the service providers. }\end{array}$ \\
\hline
\end{tabular}

Based on the input-throughput-output-feedback theory (Liebler and McConnell, 2011) and empirical studies, the relationship between the elements can be suggested for the SES Model (see Figure 3). In particular, the input information assimilates from the outside of the organisation, External Environment, as well as from within the organisation as Service Vision about ESD service provision. Whilst some suggest that the external environment plays a main role in organisational change (Burke and Litwin, 1992), others also mention the input from within the organisation (Liebler and McConnell, 2011). From the empirical studies both elements provide an input into the change process, yet it is Service Vision which is developed internally, that has a greater impact on the change process. This is particularly highlighted in case of schools developing ESD despite the change within the governmental policies. This vision becomes an input into the organisational structures and processes including Organisational Strategy, Organisational Culture, Organisational Leadership and Organisational Structure and ESD Partnership, to lead to the value co- created for the User/Organisation/Service Provider. The value that has been co-created is fed back to the Service Vision and to the External Environment, which may lead to changes within the external environment and to possible readjustment of the Service Vision. 


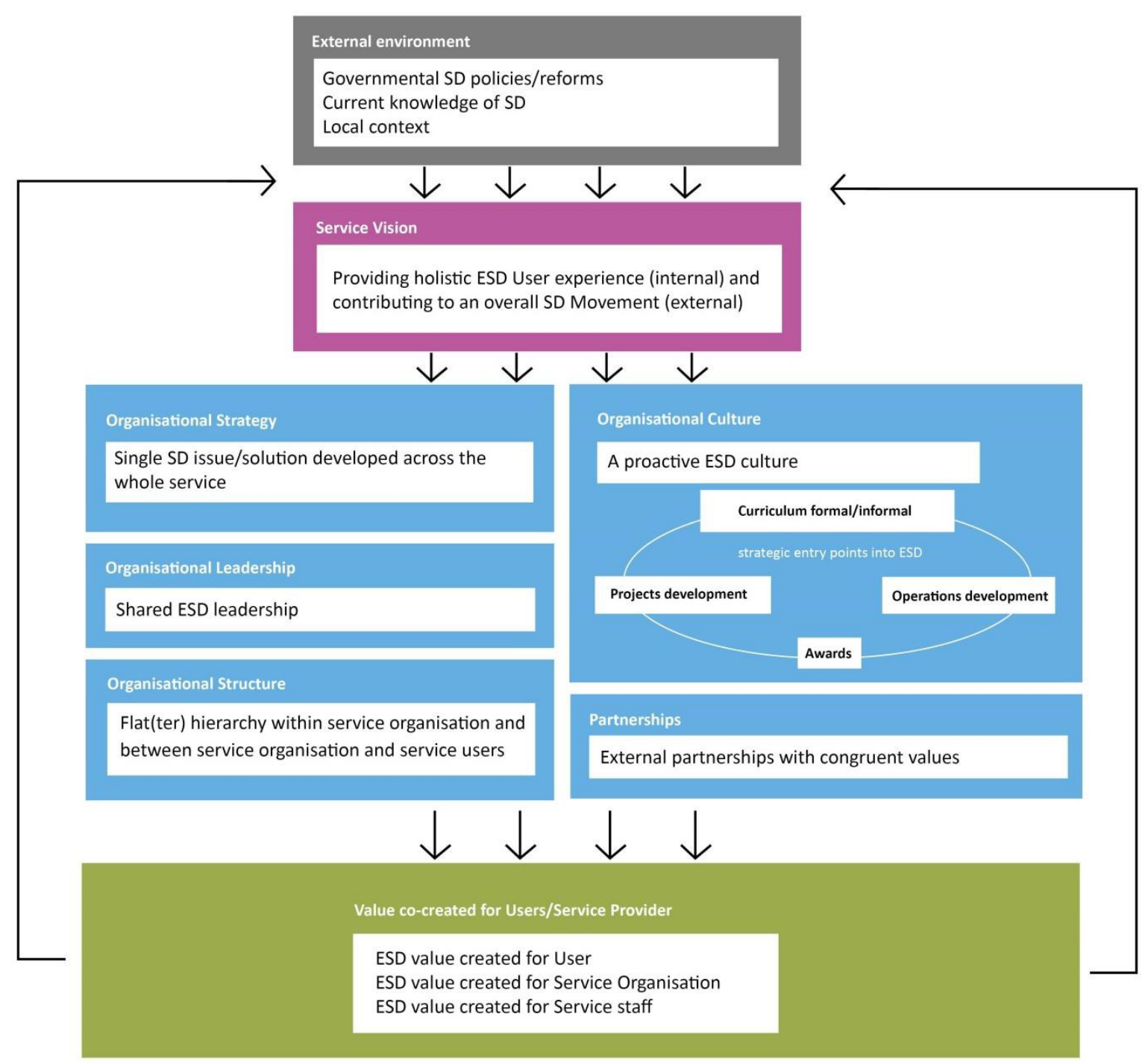

Figure 3: Sustainable Education Service (SES) Model Overview

\subsubsection{Project element of the SES Model expanded}

Each element of the model can be further expanded. For example based on the empirical study projects are a means for the school to integrate sustainable development into the service provision and it has potential for the school to integrate it at the 'whole school' level. A school that is developing an ESD project needs to consider several variables: the type of the project that is being developed, the characteristics of the project, and the lifecycle of the project. 


\section{Types of projects}

Acquisition of a large resource

Project to support larger resources

Investigative projects

Behaviour enabling/awareness raising projects

Educative community projects

Prototype projects

Characteristics of the projects

Project to have impact in: curriculum

(formal/informal), Operations, Community,

School grounds

Project has further implications

Project is short term/long term

It involves small groups/whole school
Project lifecycle

udents/staff/stakeholder involvmenet

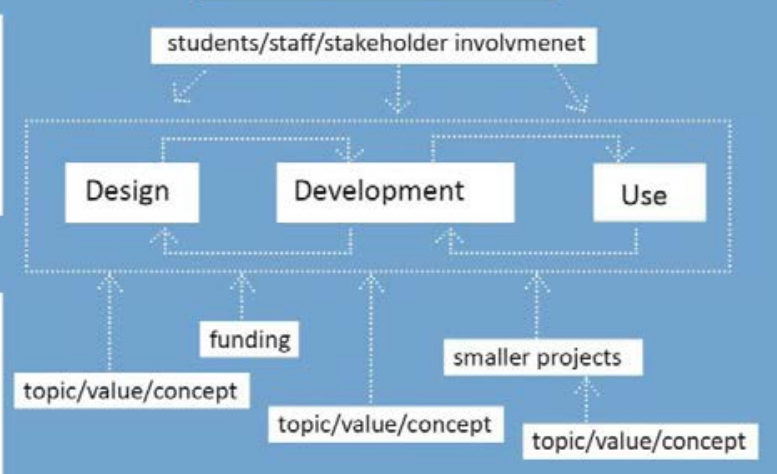

Figure 4: Project element of the SES Model

A school may engage in many types of projects with different aims and life spans. Some types of projects relate to others, as one project may become an input or output of the other. Based on the research, schools engaged in ESD, recognise these different types and engage with them strategically based on their vision and strategy. From the empirical study it was recognised that projects have a lifespan that consists of three stages of 'design, development and use'. Each stage is an opportunity for the school to embed a sustainable development issue and consider the scope of the user, service staff and other stakeholders' participation. The model shows that each project can be developed afresh or further developed. In addition, evaluation of the project may provide an opportunity to consider how the project can be self-sustained. It is these considerations that help the service to embed sustainable development at the deepest level. In addition it recognises the need for the utilisation of resources and financial constraints that all schools, as public service organisations, experience.

In addition to the type of project and its lifespan, school services need to consider other project characteristics. For example, what is the project's primary impact, whether it is curriculum, operations, community, or school grounds and whether the project integrates any of these elements on a secondary basis? Whether the project is long or short term, and what is the scope of its participants, throughout and upon its completion. This may also be considered in terms of projects' impact during its development as well as after, based on its long-term implications. Schools that are deeply engaged with ESD seek to engage with the widest variety of projects (types and characteristics) whilst considering each stage in a project's lifespan.

\subsection{Methods}

Sense-making (Ancona, 2011) refers to the process during which a new system is explored and structured by individuals for the purposes of being able to act on it. The aim of this study was to investigate whether service designers can engage with a content model developed in the previous section. As the shared understandings of a particular group (DiCicco- Bloom and Crabtree, 2006) was investigated, purposive sampling was important for this stage. To explore Service Design as a field in relation to ESD, both 
academics and practitioners were engaged. Table 2 shows general profiles of participants which included six Service Design practitioners and one Service Design academic.

Table 2: Profiles of Service Designers

\begin{tabular}{|l|l|}
\hline Service Designers & Profiles \\
\hline Participant 1 & $\begin{array}{l}\text { Service and UX designer (USA) with 8 years of industry } \\
\text { experience. Most work relates to social change, } \\
\text { education and community. }\end{array}$ \\
\hline Participant 2 & $\begin{array}{l}\text { Student experience project manager, University of } \\
\text { Derby, last 3 years leading projects on improving student } \\
\text { experience through Service Design. }\end{array}$ \\
\hline Participant 3 & $\begin{array}{l}\text { Service and UX designer (UK) with 3 years of design } \\
\text { industry experience. Most work relates to using Service } \\
\text { Design in motivation and change of behaviour projects. }\end{array}$ \\
\hline Participant 4 & $\begin{array}{l}\text { Service and UX designer (UK) with 9 years of industry } \\
\text { experience. Most work relates to enhancing } \\
\text { product/service systems through user experience. }\end{array}$ \\
\hline Participant 5 & $\begin{array}{l}\text { Service Design academic at Loughborough University } \\
\text { (UK). Most recent research relates to relational messages } \\
\text { in design and strategies for Service Design. }\end{array}$ \\
\hline Participant 6 & $\begin{array}{l}\text { Founder of a design thinking and Service Design agency } \\
\text { (UK chapter) with 30 years of experience in design } \\
\text { industry. Most current work relates to the use of design } \\
\text { thinking in service management and development. }\end{array}$ \\
\hline Participant 7 & $\begin{array}{l}\text { Founder of a Service Design consultancy in the UK, } \\
\text { working on both private and public service projects. }\end{array}$ \\
\hline
\end{tabular}

During the sense-making process participants were sent a package describing the study. The package was used to conduct in-depth interviews with each participant. It sought to investigate whether the model was appropriately developed and whether it was suitable for service designers to use in the design process with educational institutions to move towards ESD.

The study sought to:

1. Understand whether service designers comprehend the model.

2. Evaluate whether the model can be used by service designers as a tool during the design process to engage with the educational institutions at the transformational level

\subsubsection{In-depth interviews with service designers}

This research stage was constructed to explore propositions about the relationship between Service Design and the content model established in the introduction and to explore other opportunities for Service Design in this context. To investigate this phenomenon, in-depth, semi-structured interviews were conducted with seven professional service designers. The interview questions were open but guided by several issues that were raised throughout the research. In particular, the potential of the model to be used as a tool by service designers was evaluated during the interviews. As a result, this provided structure for each individual interview, increasing the reliability of its outcome.

\subsubsection{Analysis of the Interviews with service designers}


Analysis of the interviews followed axial/open coding, additional comments were written up during the process. Memos were written up during and after interviews and used to develop and expand themes from the data. The development of the themes/concepts was also guided by service designers' sensemaking process of ESD by exploring the SES Model.

\subsection{Findings}

\subsubsection{Understanding the model}

The initial part of the sense making session involved service designers trying to understand the model itself. The model therefore became the point of discussion for designers rather than a definitive vision for implementation. Few participants recognised that educational institution is portrayed as a service system, and valued the attempt of the model to show it holistically. They recognised that the model represents a particular relationship between students and the service. Others however, although understood that the holistic model shows the school as a service system, expressed scepticism at the very start of the interview. Some were not sure whether the 'student is the main user', arguing that the model needs to reflect a variety of stakeholders. For others, the representation of the educational system on an organisational level seemed too focused. The model, prompted some designers to agree whilst others to disagree about who this service is for and by whom it is provided. One set of designers focused on the change in the content of educational service in relation to sustainable development at organisational level (as presented by the model). Other set of designers explored the content of another educational system altogether. Both sets however used SES Model in what Young (2008) calls engaging designers in designing educational 'contexts' rather than 'in contexts'. The value here is in designers having a tool that prompts them to gage with 'what' is being designed and not only 'how' something is being designed.

\subsubsection{Partnership element}

Most designers were able to engage with the model holistically and engage with each element, interpreting its individual components. Some elements generated little interest from the interviewees, for example, the 'structure' element of the model. Whilst the aim of that element was clear to the interviewees, it initiated the least discussion from them. Some elements generated more enthusiasm than others. The partnership element was the most interesting element for the participants. Most participants agreed that partnership is integral part of any organisation, recognising that there is a large number of partners that an organisation could have. Some participants also recognise that 'partnership' is an increasingly important element in education as a whole in order to survive in the changing environment. It is also seen as a strategy for educational institutions to innovate. 'Partnership' element therefore has been valued by most interviewees; and few were able to recognise the purpose of 'partnership element' in the context of education for sustainable development as illustrated in the model.

\subsubsection{Model and its application}

In addition to engaging with what is being presented, some of the designers also questioned credibility of the model. Several participants expressed wariness about the model if they were to use it in its current state in a Service Design project. Smith and Marrow (1999) note that designers tend to question credibility of the academic models, as these models cannot convince practitioners of their realism. Bringing in case studies has been seen as a means to validate the model and the research to the Service Design community. As the context of sustainable education was novel for the service designers, it was felt that more contextual information would be needed for designers to feel comfortable to work within the context.

Credibility of the model thus was undermined without additional visual data. This limitation highlighted the importance of visual language in the development of new tools and methods for service designers. It 
is well known that one of the primary principles of service designers is to visualise the intangible aspects of services and visual language is an important element of service development and design (Segelstrom, 2010). However, it is not always clear what this means for the service designer's knowledge acquisition. Research developed by Lieberman (1995) found that for graphic designers, a knowledge acquisition system needs to have graphical interface and be example based. Research by Lofthouse (2001) and Escobar-Tello (2011) further identified this to be important for industrial designers. Findings from the research concur with these statements. The visual communication of the new method or tool is vital for service designers to successfully acquire knowledge about a represented entity. However, providing case studies and examples as requested by service designers and identified by research, is challenging. In particular, the fear is to limit the design outcomes by pre-defining them in advance through examples.

\subsubsection{Using SES Model in the design process}

During interviews participants were asked to make sense of the model as means to understand change in schools at the organisational level and discuss its applicability during the service design process as they imagined it in use. As a result designers imagined three scenarios in use that are presented below.

\section{Scenario 1. Using the Model to pitch the projects}

The initial barrier in a real life design project, defined by the interviewees, has been the initial stages of the project procurement, where a Service Design project is initiated with a stakeholder. In this scenario, the service designer uses the model to pitch the idea to a stakeholder in order to start an ESD project. There are two possibilities discussed:

1. The pitch is done by a service designer directly to the school.

2. The pitch is done by a service designer on behalf of the school to the sponsor.

In the first scenario there is a recognised barrier of 'getting the foot in the door'. The model is seen as a tool to communicate the value of change by showing the impact it may have on the school and the student as well as what the change process entails. It therefore allows service designers to make a 'business case', to illustrate their understanding of the system and its potential improvement. In this case, service designers are initiating change towards ESD and are pitching their services to the school or to the local government. The model is there to illustrate the change and to break the barrier between the Service Design community and educational/governmental community.

In the second scenario, the service designer is working for the school and uses the model to develop different projects to pitch to external organisations and therefore develop partnerships. The model therefore can be used as a structure from which different scenarios can be developed and illustrated. It is a tool that can be used in the co-creation stage between the school and the service designer to define aims, values and impacts. These scenarios are pitched to selected organisations depending on the aim of the project. In this scenario, the service designer uses the model to engage with the school on a participatory level. This scenario is also developed to enable one aspect of the model, school partnerships, to become reality.

\section{Scenario 2. Using the Model during research and design stages}

In this scenario, the service designer is hired directly by the school and works directly with a school on creating change towards ESD at a grass roots level. The initial stages of the design process in the project are the research/discovery phase where the aim of the service designer is to understand the holistic ecosystem of the school. It is in this stage that the model is imagined to be used. Here the model is defined as an 'ideal ecosystem' and 'the story of the school' that is moving towards ESD. Using this 
'ideal ecosystem' model, the service designer begins the research stage with more focus. They are able to research for greater details based on the different elements and relationships of the model.

Participants explain that in a real world scenario, after the ecosystem has been developed the brief will be created with the client. The model would be used in the conversation with the school to discover and develop the initial brief. Having a holistic model with modular elements (see Figure 3) would allow service designers to engage with schools on a deeper level, analysing individual elements of the school whilst seeing the system holistically. "It means the service designer can choose to work on a whole systems level or 'hone in on an area'. Once focused on one area, the model is specific enough (see Figure 4) to help develop a concrete brief. The detailed view of the element shows a comprehensive set of touch-points that interrelate and should be taken into the account. This is valued by the service designer in their decision making process during research stage. The model becomes both an evaluative and decision-making tool for analysing the current situation and developing a more specific brief with the school.

\section{Scenario 3. Using the Model as a Brainstorming tool to develop projects}

During the interviews, the project element of the model (see Figure 4) has been identified by the service designers as means to engage with the schools at transformational level. The project element alongside other elements of the model elicited project scenarios from the participants (see Table 3).

Table 3: Projects brainstormed by service designers using SES Model

\begin{tabular}{|l|l|}
\hline Project 1 & $\begin{array}{l}\text { "Why not contact companies that sell composting bags, show } \\
\text { them your project, and show how in the future kids will be more } \\
\text { sensitive to it, and their profit will increase because they will be } \\
\text { aware of it. Why not sponsor us to teach kids about your } \\
\text { products? Because kids will talk about it at home with parents" } \\
\text { (Participant 5) }\end{array}$ \\
\hline Project 2 & $\begin{array}{l}\text { "UK school buildings if they were open all hours... they are } \\
\text { only used 13\%. Why don't multiple schools get together, reduce } \\
\text { asset use dramatically, but operate the school on a shift based } \\
\text { system" (Participant 6) }\end{array}$ \\
\hline
\end{tabular}

These projects incorporate many elements of the model that would make a school move towards sustainable development successfully, such as building a partnership in a win-win situation, developing school projects that are integrated into the curriculum, educating immediate community - the parents, partnerships and the use of the school's resources. While these projects were brainstormed by service designers on their own, they felt that they could also be co-designed with the schools using the model in a workshop environment.

These highlight the successful use of the model by service designers in the context of ESD. In these scenarios, as imagined by the service designer, the model has multiple uses. When mapped onto service development process model adapted by Sangiorgi et al. (2015) from Johnson et al (2000) it illustrates how its use is particularly valuable at the early stages of the service design (see Table 4). It may be used as a knowledge tool for service designers to validate their engagement in the subject area and procure services from the educational institutions. It may also be used as a co-creation tool in the participatory design process of a research stage. Further the model can be used as a brainstorming tool by service designers alone to imagine and develop design-led projects. 
Table 4: Application of SES Model in service development process, adapted from Sangiorgi et al., (2015), represented in a linear rather than cyclical version.

\begin{tabular}{|c|c|c|}
\hline & $\begin{array}{l}\text { New Service Development } \\
\text { Process (Sangiorgi et al., 2015) }\end{array}$ & $\begin{array}{l}\text { SES Model use in the Service } \\
\text { Development Process }\end{array}$ \\
\hline \multirow[t]{2}{*}{ Procurement } & \multirow{2}{*}{$\begin{array}{l}\text { Procurement of the service by the } \\
\text { client }\end{array}$} & Pitching of the project to the school \\
\hline & & $\begin{array}{l}\text { Pitching the project on behalf of the } \\
\text { school to the external sponsor }\end{array}$ \\
\hline \multirow[t]{2}{*}{ Research } & \multirow[t]{2}{*}{ Research undertaken for the project } & $\begin{array}{l}\text { Researching holistic school } \\
\text { ecosystem }\end{array}$ \\
\hline & & $\begin{array}{l}\text { Researching one element of the } \\
\text { school in detail }\end{array}$ \\
\hline \multirow[t]{3}{*}{ Design } & \multirow{3}{*}{$\begin{array}{l}\text { Formulation of new service } \\
\text { objective /strategy } \\
\text { Idea generation and screening } \\
\text { Concept development and testing }\end{array}$} & Developing brief with the school \\
\hline & & Brainstorm design-led projects \\
\hline & & $\begin{array}{l}\text { Designer co-creates projects with } \\
\text { schools }\end{array}$ \\
\hline Analyse & $\begin{array}{l}\text { Business analysis } \\
\text { Project authorisation }\end{array}$ & \\
\hline Develop & $\begin{array}{l}\text { Service design and testing } \\
\text { Process and system design and } \\
\text { testing } \\
\text { Marketing programme design and } \\
\text { testing } \\
\text { Personnel testing } \\
\text { Service testing and pilot run } \\
\text { Test marketing }\end{array}$ & \\
\hline Launch & Full launch and post-launch review & \\
\hline
\end{tabular}

\subsubsection{Bringing process into the model}

The original purpose of the content model was to develop 'an idealised representation of how a system works' (Johnson and Henderson, 2002) for service designers to use as a tool at an organisational level. Whilst designers were able to engage with it as researcher intended, they expressed concern about the use of the model at the very start of the sense making study. As the aim for developing the SES Model was its use in the design process, this is an important barrier to its future application.

For some designers the main issue was the form of the model. The 'flatness' of the model created an undesirable pre-defined view of the goal. Several participants reflected on how projects that happen in real life require greater 'flexibility', for example customers require space to create their own agenda. Participants reflected on how service designers work, and the need for a service designer to have 'flexibility' as well as 'organisation' in their projects.

Participants proposed to include a hierarchy in the model. For example, it was recognised that the model has an internal organisational process that should be followed in order to develop education for sustainable development. It was suggested that this process of priorities, needs to be highlighted in the 
model. The hierarchy would also differentiate the overall process from the individual elements that include a series of possible configurations, for example as a 'menu options'.. This should allow for the necessary flexibility in the model. Few suggested that the model is converted into a deliverable framework, focusing on the action of solution delivery.

As the model has been developed by the researcher to be put into practice by the service design practitioner, the 'model-world' relationship Weisberg (2007) needs to be extended to not only represent the new system but also to reflect the service design process of participation and co-creation as it takes place in the real world projects. This finding showed that the credibility (Smith and Morrow, 1999) of the model was undermined when only "know that" knowledge was portrayed through the model. It also suggests that if the model integrated the design process or "know how" knowledge, there would be a higher understanding of the model and a greater chance of its uptake by the designer. This is important to consider when models and tools are created externally to the design practitioner, such as in academic environment, with an expectation that the design practitioner will use it.

\subsubsection{Service designers as leaders of change - a practical outlook}

The content model developed through this research provides constraints and a vision that are placed upon the service system not only by an individual organisation but also by wider environmental, social and economic issues. Using the model necessitates service designers to be engaged with the issues of sustainable development as well as having a capacity of working at transformational level. The sensemaking study revealed that there is a gap in interest and capacity within service design community to engage with the issue at the intended organisational level.

A discussion with service designers reviewed the assumption that all designers are 'change agents'. Research found that service designers feel more comfortable with such terms as 'change' and 'innovation' as defined in collaboration with the client rather than promoting their own agenda. At the same time, it was also suggested that service designers are malleable and the broad application of Service Design to a multitude of contexts means that service designers just need to be steered and engaged with the agenda. Examples of 'movements' within Service Design could be exemplified by such networks as Design for Social Innovation (DESIS). This research is seen as an attempt to further develop awareness of change towards sustainability in public service within the Service Design community.

Yet, discussion with service design practitioners revealed that having an interest in a particular problem is not enough for Service Design community to address it. In particular, one of the main questions being asked is whether a Service Design practitioner has space to get involved in such projects. This discussion is rooted in the scope of change that the model presupposes and the potential impact of this change. It was recognised that the model shows innovation and change at the grass roots level. Grass roots and bottom-up change is well positioned in the literature on sustainable development, as it enables organisations to respond to the local needs and values of the communities involved (Seyfang and Smyth, 2007). All participants agreed that grass roots change is an important type of change. It can be a positive development within individual environments and it has been viewed as a way to create a cultural change within organisations. And yet, service designers are limited by the opportunities of the system within which they operate. Grass roots level projects that would result from the use of the model, are energy intensive with little profit and stability, making such scenario unrealistic for the service design practitioners who would usually work in a medium-size consultancy. This reflects the current climate within which Service Design consultancies work, where they struggle to survive and to engage with projects for social change, especially in the public sector. There are examples of design organisations such as Innovation Unit (Hannon, 2007) who began their work as a response to the need for innovation in the public sector, but experienced financial challenges and found themselves expanding into the private sector. The challenge in this situation is that for service designers to work at the grass roots level as 
proposed by the model, schools need to have a capability to procure design services. However, the reports on trends in educational spending in the UK shows that besides day-to-day spending on teacher pay and consumables, most of the school spending has been in areas of new build and ICTs (Chowdry and Sibieta, 2011). Schools therefore do not show a habit of spending a lot of money on innovation programs or projects. The Institute for Fiscal Studies report (Sibieta, 2015) projects cuts in the educational sector for the next five years, in addition to the funding being transferred directly to the schools, making them more autonomous in their spending (Gov.uk, 2013). It therefore may be projected that schools being more autonomous in their spending may not have the capability or motivation to spend their money on innovation in the current economic climate. Participants drawing on their personal experience suggested that this situation means schools will not be hiring a Service Design consultancy directly to engage in a design project.

These findings are in line and support the need for 'better commissioning models for design' in public services expressed by several authors of Design Commission and Nesta (Design Commission, 2013 and Mulgan, 2014). Some examples proposed by the interviewees included developing hubs and partnerships with the local authorities and educational institutions. Another proposed model for enabling transformational change through Service Design is for a governmental body or educational body creating a Service Design position within it. This is another timely proposition that reflects current recommendations of Design Commission to the government, as well as design community. It reads "department leaders must create career paths for social and Service Design professionals in public service work" (Design Commission, 2013: 17). Further, the Commission states that this issue relates to all designers who have an interest in working in the public sector and that there are very few opportunities to do so.

\section{Conclusion}

This research suggests that a content model, developed to be used at transformational level may be of value to service designers. The model allowed service designers to view change at organisational level instead of individual level. In addition, scenarios in use developed by designers demonstrated how the model could be used to enable action learning for the individual schools. However, various barriers have been identified for the use of the SES content model by service design practitioners, including its form, alignment with service design vision about education and the practicalities of real life projects. In light of these issues, several conclusions may be drawn. Designers are action oriented and in order for them to engage in a new context, 'know that' knowledge needs to be supplemented with 'know how' knowledge. Designers' vision needs to align with the vision of the model. For this the model needs to be closer aligned with the service design process and presented in such a way as to relay the need for the specific change. Finally, Service Design practitioners are not placed to engage with educational institutions to bring about change on a grass roots level. This limitation plays a major barrier in the role of service designers as transformational change agents in education. Future research should seek to address these issues.

\section{References}

Akbayrak, B., (2000) 'A comparıson of two data collectıng methods: interviews and quest1onna1res’, Hacettepe Üniversitesi Eğitim Fakültesi Dergisi, Vol.18 No.18, pp.1-10

Ancona, D. (2011) 'Sensemaking: Framing and Acting in the Unknown', In Snook, S. et al (Eds.) The handbook for teaching leadership: Knowing, doing, and being, Sage Publications Inc., pp. 3-19 
Bonnett, M. (2006) 'Education for sustainability as a frame of mind': Reprinted from Environmental Education Research (2002) Vol. 8 No.1, pp. 9-20, Environmental Education Research, Vol. 12 No.3-4, pp. 265-276

Bourn, D. (2008) 'Education for sustainable development in the UK: Making the connections between the environment and development agendas', Theory and research in education, Vol. 6 No. 2, pp. 193206

Brooks-Wilson, S., Snell, C. (2012) '"Hard to Reach" or "Accessible When Approached"? Sustainable Development Discussions with Marginalized Pupil Groups', Children, Youth and Environments Vol. 22 No. 2, pp. 1-24

Bryman, A. (2004) Research methods and organization studies, $2^{\text {nd }}$ ed., Routledge, London.

Burke, W.W., Litwin G.H. (1992) 'A causal model organizational performance and change', Journal of Management, Vol.18, pp.523-545.

Chowdry, H., Sibieta, L. (2011) Trends in Education and Schools Spending (IFS Briefing Note BN121), Institute for Fiscal Studies, London. www.ifs.org.uk/bns/bn121.pdf (Accessed July 5, 2015)

Cipolla, C., (2012) Solutions for Relational Services. In Miettinen, S.and Valtonen, A. (Eds.), Service Design with Theory. Discussions on Change, Value and Methods, Rovaniemi: LUP - Lapland University Press.

Clatworthy, S. (2011) 'Service innovation through touch-points: development of an innovation toolkit for the first stages of New Service Development', International Journal of Design, 5(2), 15- 28.

Delaney, L.J. (2017). 'Patient-centred care as an approach to improving health care in Australia’,. Collegian, https://doi.org/10.1016/j.colegn.2017.02.005. (Accessed August 25, 2017)

Denzin, N. K., Lincoln, Y. S. (Eds.), (1998) Collecting and Interpreting Qualitative Materials, SAGE Publications.

Design Commission (2013) Design for public good [online].

https://www.designcouncil.org.uk/knowledge-resources/design-public-good (Accessed June 1, 2015)

DiCicco-Bloom, B., Crabtree, B. F. (2006) 'The qualitative research interview', Medical Education, Vol. 40 No. 4, pp. 314-321.

Escobar-Tello, M. C. (2011). Explorations on the relationship between happiness and sustainable design Ph.D. Thesis. Loughborough University, Loughborough.

Freire, K. and Sangiorgi, D. (2010) Service design and healthcare innovation: From consumption to coproduction and co-creation, In 2nd Nordic Conference on Service Design and Service Innovation, Linkoping, Sweden,

Gov.uk (2013) Giving local authorities more control over how they spend public money in their area https://www.gov.uk/government/policies/giving-local-authorities-more-control-over-how-they-spendpublic-money-in-their-area--2 (Accessed May 20, 2015) 
Grönroos, C. (2008) 'Service logic revisited: who creates value? And who co-creates?' European Business Review, Vol. 20 No. 4, pp.298 - 314.

Hannon, V. (2007) Next practice in education: a disciplined approach to innovation. London: The Innovation Unit, http://www.schoolsworkingtogether.co.uk/documents/nextpractice_in_education.pdf (Accessed August 14, 2017)

Henderson, G. M. (2002) 'Transformative learning as a condition for transformational change in organizations', Human Resource Development Review, Vol. 1 No. 2, pp. 186-214.Huberman, M., Miles, M. B. (2002) The qualitative researcher's companion. Sage: Newbury Park, CA.

Johnson, J., Henderson, A. (2002) 'Conceptual Models: Begin by Designing What to Design', Interactions, Vol. 9 No. 1, pp. 25-32.

Junginger, S., Sangiorgi, D. (2011) 'Public policy and public management: contextualising service design in the public sector'. In R. Cooper et al (Eds.), The Handbook of Design Management, Berg Publishers, Oxford University, Oxford, pp. 480-494.

Kahn, R. (2008) 'From education for sustainable development to ecopedagogy: Sustaining capitalism or sustaining life’ Green Theory and Praxis: The Journal of Ecopedagogy, Vol. 4 No. 1, pp.1-14

Kopnina, H., Meijers, F. (2014) 'Education for sustainable development (ESD): Exploring theoretical and practical challenges’, International Journal of Sustainability in Higher Education, Vol. 15 No. 2, pp.188-207

Kuure, E., Miettinen, S., Alhonsuo, M. (2014) 'Change through Service Design-Service Prototyping as a Tool for Learning and Transformation', In DRS 2014 Proceedings

http://www.drs2014.org/media/654218/0243-file1.pdf (Accessed August 9, 2015)

Limerick, D., Passfield, R., Cunnington, B. (1994) 'Transformational Change: Towards an Action Learning Organization’, The Learning Organization, Vol. 1 No. 2, pp. 29 - 40

Liebler, J., McConnell, C. (2011) Management principles for health professionals, Jones \& Bartlett Publishers, Canada.

Lofthouse, V. (2001) Facilitating Ecodesign in an Industrial Design Context: An Exploratory Study School of Industrial and Manufacturing Science Enterprise Integration, Ph.D. Thesis. Cranfield University, Cranfield.

Mendel, J. (2012) 'A taxonomy of models used in the design process', Interactions, Vol. 19 No. 1, pp. 81-85

Miettinen, S. (2016) An introduction to industrial service design, Routledge, Abingdon.

Miles, M. B., Huberman, A. M. (1994) Qualitative data analysis: An expanded sourcebook, Sage Publications, London.

Mulgan, G. (2014) Design in Public and Social Innovation [online]

http://www.nesta.org.uk/publications/design-public-and-social- innovation (Accessed January 23, 2015) 
Ng, I. C. L., Jeannie, F. (2009) 'Education as Service: The Understanding of University Experience Through Service Logic’, Journal of Marketing for Higher Education, Vol. 19 No. 1, pp. 38-64

Pedler, M., Burgoyne, J. G., Brook, C. (2005) 'What has action learning learned to become?', The Revans Institute for Action Learning and Research (New directions series of occasional papers), Vol. 2, No. 1, pp. 49-68

Rigg, C. (2008) 'Action learning for organizational and systemic development: Towards a 'both-and' understanding of 'I' and 'we', Action Learning: Research and Practice, Vol. 5 No. 2, pp. 105-116

Robson, C. (2002) Real world research, $2^{\text {nd }}$ ed., Blackwell, Oxford.

Sangiorgi, D., Prendiville, A., Jung, J. and Yu, E. (2015) Design for Service Innovation and Development: Final Report. [online] Lancaster University, Lancaster, UK. http://imagination.lancs.ac.uk/sites/default/files/outcome_downloads/desid_report_2015_web.pdf (Accessed August 10, 2017)

Schein, E. H. (1990) ‘Organizational Culture’, American Psychologist, Vol. 45 No.2, pp.109-119

Schermann, M., Böhmann, T., Krcmar, H. (2009) 'Explicating Design Theories with Conceptual Models: Towards a Theoretical Role of Reference Models’, In Becker J. et al, Wissenschaftstheorie und gestaltungsorientierte Wirtschaftsinformatik, pp.175-194

Segelström, F. (2010) Visualisations in Service Design, Linköping University, Linköping, Sweden.

Service Design Research Network (SDR) UK (2013) Building the Service Design Research UK Landscape, [online] Lancaster University, UK http://imagination.lancaster.ac.uk/sites/default/files/news_downloa ds/sdruk_-_workshopreport_1.pdf (Accessed March 14, 2015)

Seyfang, G., Smith, A. (2007) 'Grassroots innovations for sustainable development: towards a new research and policy agenda’, Environmental Politics, Vol.16 No. 4, pp. 584-603.

Shallcross, T. (2005) Whole school approaches to education for sustainable development through school-focused professional development (The SEEPS project) [online] http://www.ceeindia.org/esf/download/paper51.pdf (Accessed June 15, 2014)

Sibieta, L. (2015) Schools spending The Institute for Fiscal Studies, IFS Briefing Notes BN168, http://www.ifs.org.uk/publications/7669 (Accessed August 29, 2015)

Smith, R. P., Morrow, J. A. (1999) 'Product development process modelling’, Design Studies, Vol. 20 No. 3, pp. 237-261

Steen, M., Manschot, M., De Koning, N. (2011) 'Benefits of Co- design in Service Design Projects', International Journal of Design, Vol. 5 No. 2, pp. 53-60

Vargo, S. L., Lusch, R. F. (2008) 'Service-dominant logic: continuing the evolution', Journal of the Academy of marketing Science, Vol. 36 No. 1, pp. 1-10 
Wals, A. (ed.) (2009) Review of Contexts and Structures for Education for Sustainable Development 2009 (DESD, 2005-2014), UNESCO: Paris [online]

unesdoc.unesco.org/images/0018/001849/184944e.pdf (Accessed February 2, 2015)

Weber, R. (2003) 'Conceptual modelling and ontology: Possibilities and pitfalls', Journal of Database Management, Vol. 14 No. 3 pp.1-20

Weisberg, M. (2007) 'Who is a Modeler?', The British Journal for the Philosophy of Science, Vol. 58 No. 2, pp. 207-233

WWF-UK (2011) Pathways: to education for sustainable development, wwf.org.uk/downloads/pathways_2011.pdf (Accessed February 16, 2015)

Yin, R. K. (1994) Case Study Research: Design and Methods,

Sage Publications: London.

Young, R. (2008). 'An integrated model of designing to aid understanding of the complexity paradigm in design practice’, Futures, Vol. 40 No. 6, pp. 562-576 